Far Eastern Entomologist

\begin{tabular}{lll}
\hline Number 438: 6-12 & ISSN 1026-051X (print edition) & September 2021 \\
\hline
\end{tabular}

https://doi.org/10.25221/fee.438.2

http://zoobank.org/References/62E2777E-3772-484E-ADD8-511D6758E756

\title{
NEOLITINIA SULPHURATA GEN. N., SP. N. (LEPIDOPTERA: GELECHIIDAE) FROM BORNEO ISLAND
}

\author{
M. G. Ponomarenko*, M. M. Omelko, N. V. Omelko
}

Federal Scientific Center of the East Asia Terrestrial Biodiversity, Far East Branch of the Russian Academy of Sciences, Vladivostok, 690022, Russia. *Corresponding author, E-mail: margp@biosoil.ru

Summary. Neolitinia gen. n. (Lepidoptera: Gelechiidae) with the type species $N$. sulphurata sp. n. is described from state of Sabah of East Malaysia. The taxonomic position of the new genus within the subfamily Gelechiinae is discussed.

Key words: Gelechiidae, Litini, Neolitinia, taxonomy, new genus, new species, Malaysia.

М. Г. Пономаренко, М. М. Омелько, Н. В. Омелько. Neolitinia sulphurata gen. n., sp. n. (Lepidoptera: Gelechiidae) с острова Борнео // Дальневосточный энтомолог. 2021. N 438. C. 6-12.

Резюме. Neolitinia gen. n. (Lepidoptera: Gelechiidae) с типовым видом N. sulphurata sp. n. описан из штата Сабах Восточной Малайзии. Обсуждается таксономическое положение нового рода в подсемействе Gelechiinae семейства выемчатокрылых молей.

\section{INTRODUCTION}

The present work is based on the material originated from East Malaysia. The collected species turned up strongly differing from known genera within family Gelechiidae on the morphology of the genitalia, that served the base for description of a new genus Neolitinia gen. $\mathbf{n}$. The combined description of a new genus and new species is given according with ICZN, Art. 13.4. (1999). The holotype and paratypes of a new species are kept in the Federal Scientific Center of the East Asia Terrestrial Biodiversity (FSC of Biodiversity), Far Eastern Branch of Russian Academy of Sciences (Vladivostok).

\section{MATERIAL AND METHODS}

Specimens were collected in the state of Sabah on the island of Borneo by the second author. The moths were collected in the vicinity of Keningau at an altitude of $950 \mathrm{~m}$ a.s.1. in 2018, and near Tawau in a lowland dipterocarp forest in 2019. All specimens were collected at light. Male and female genitalia were prepared following Falkovitsh \& Stekolnikov (1978) and stained with Chlorazol black. Genitalia were studied in glycerol using a Nikon SMZ-10 stereomicroscope then mounted in Euparal following Robinson (1976). Terminology follows Klots (1970) and Ponomarenko (2005). Photographs of adults were made with a Nikon D300 
camera equipped with a $50 \mathrm{~mm}$ macro lens. Photographs of genitalia slides were taken using Nikon SMZ25 microscope with an incorporated digital camera and Olympus SZX16 microscope with DP74 Nikon digital camera. Descriptions of the new species are accompanied by line drawings of male genitalia.

\section{DESCRIPTION OF NEW TAXA}

Neolitinia Ponomarenko, M. Omelko et N. Omelko, gen. n.

http://zoobank.org/NomenclaturalActs/27CEAD48-8A93-40A4-BAB8-5B29145AA893

Type species: Neolitinia sulphurata $\mathbf{s p .} \mathbf{n}$.

DIAGNOSIS. The new genus can be recognized by the absence of the uncus and gnathos. The tegumen is a small arched plate. The cucullus is wide, lobe-like, its medial side joined with a strongly sclerotized glandiductor. Vinculum, juxta and both sacculi fused into a single ventral sclerite enveloping the ventral and lateral surfaces of the aedeagus (Figs 6-9). The female genitalia are characterized by the elongate apex of the papillae anales, ostium and antrum covered by an antevaginal plate with a honeycomb pattern on medial surface, and the signum shaped like an arched triangular plate with a rounded apex (Figs 10-14).

Neolitinia is somewhat similar to genera of Litini that have well-developed, sclerotized glandiductors with a more or less wide base - Schistophila Chrétien, 1899; Schneidereria Weber, 1957; Parastenolechia Kanazawa, 1985; Teleiodes Sattler, 1960, etc. The differences between the new genus and genera listed above are in the morphology of the tergal part of the male genitalia. The tegminal structures are absent or reduced in N. sulphurata, whereas all known species in the tribe Litini, including those in the genera mentioned above, have more or less an elongated distally tegumen, a well-developed uncus, and often a strong gnathos (if present). Likewise, the leaf-shaped and wide at the base cucullus in N. sulphurata is quite different than in other species of Litini. All known species in this tribe have a rather slender cucullar part of the valva, if present, which was previously confirmed through functional morphological study (Ponomarenko 2005).

ETYMOLOGY. The generic name is derived from the name of the tribe combined with the prefix "neo" (Greek = "new"), meaning new member of Litini.

Neolitinia sulphurata Ponomarenko, M. Omelko et N. Omelko, sp. n.

http://zoobank.org/NomenclaturalActs/46A4F9BA-0A2B-4739-B82D-DB992C9C6CE1

Figs $1-14$

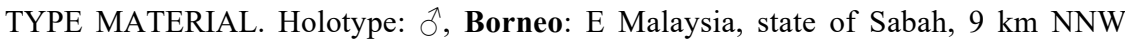
Keningau, 25.III 2018 (leg. M. Omelko), gen. slides 149 MP, Euparal. Paratypes: 1 , same locality, 19.III 2018; gen. slides 161 (f) MP, Euparal; 1 ô, 24 km N Tawau, 19.VIII 2019 (leg. M. Omelko); gen. slides 160 (m) MP, Euparal.

DIAGNOSIS. The new species is distinguishable by having a wide leaf-shaped cucullus; glandiductor inflated basally and heavily narrowed distally, bearing a small, rounded lobe at the apex; sternal part of genitalia with two pairs of processes - ventral processes of juxta bearing strong thorns at the apex; and lobe-like, setaceous lateral processes in the male genitalia. It is determined by finger-like apices in the papillae anales; honeycomb-patterned antevaginal plate with triangular centered sclerotization covering the ostium and antrum ventrally; and arched, triangular signum with a rounded apex in the female genitalia. 
DESCRIPTION. Adult (Figs 1, 2). Forewing length 3.0-3.2 mm. Head pale sandy, unicolorous, or with scattered scales dark on top. Antennal scapus pale sandy with brownish or blackish bands, flagellum with alternating dark grey and blackish segments. Basal segment of labial palpus pale sandy or brownish; second segment longer than third, widened distally, pale sandy with disseminated brownish scales or brownish with white distally; third segment white with two black bands near base and beyond the middle. Forewings sandy with intensive darkening in male and pale sandy with scattered brownish scales in female; proximal half of
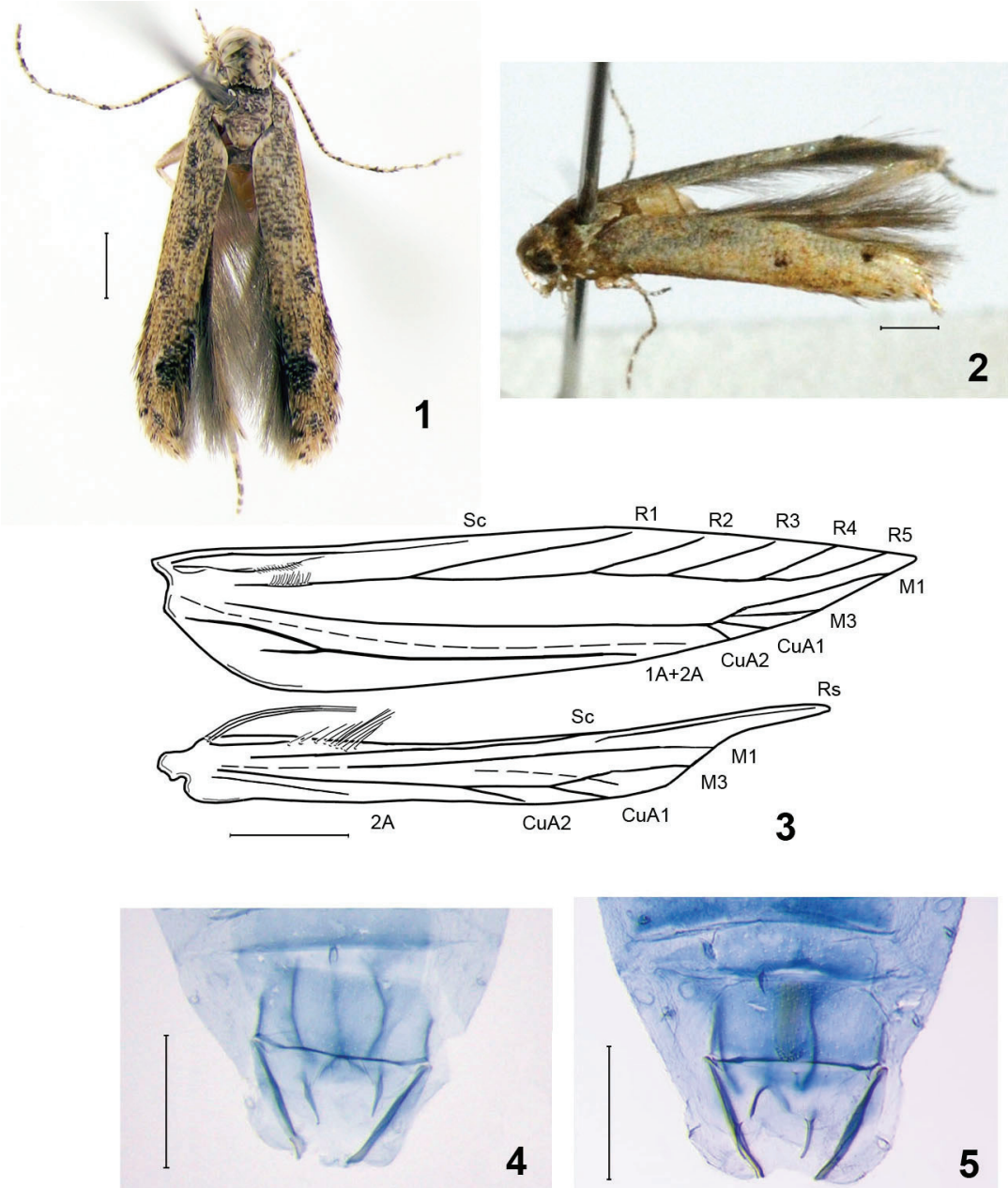

Figs 1-5. Neolitinia sulphurata sp. n. 1 - adult, male, holotype; 2 - ditto, female, paratype; 3 - wing venation; 4 - 2nd sternite, female; 5 - 1st and 2nd tergites, male. Scale bar 0.5 $\mathrm{mm}$. 

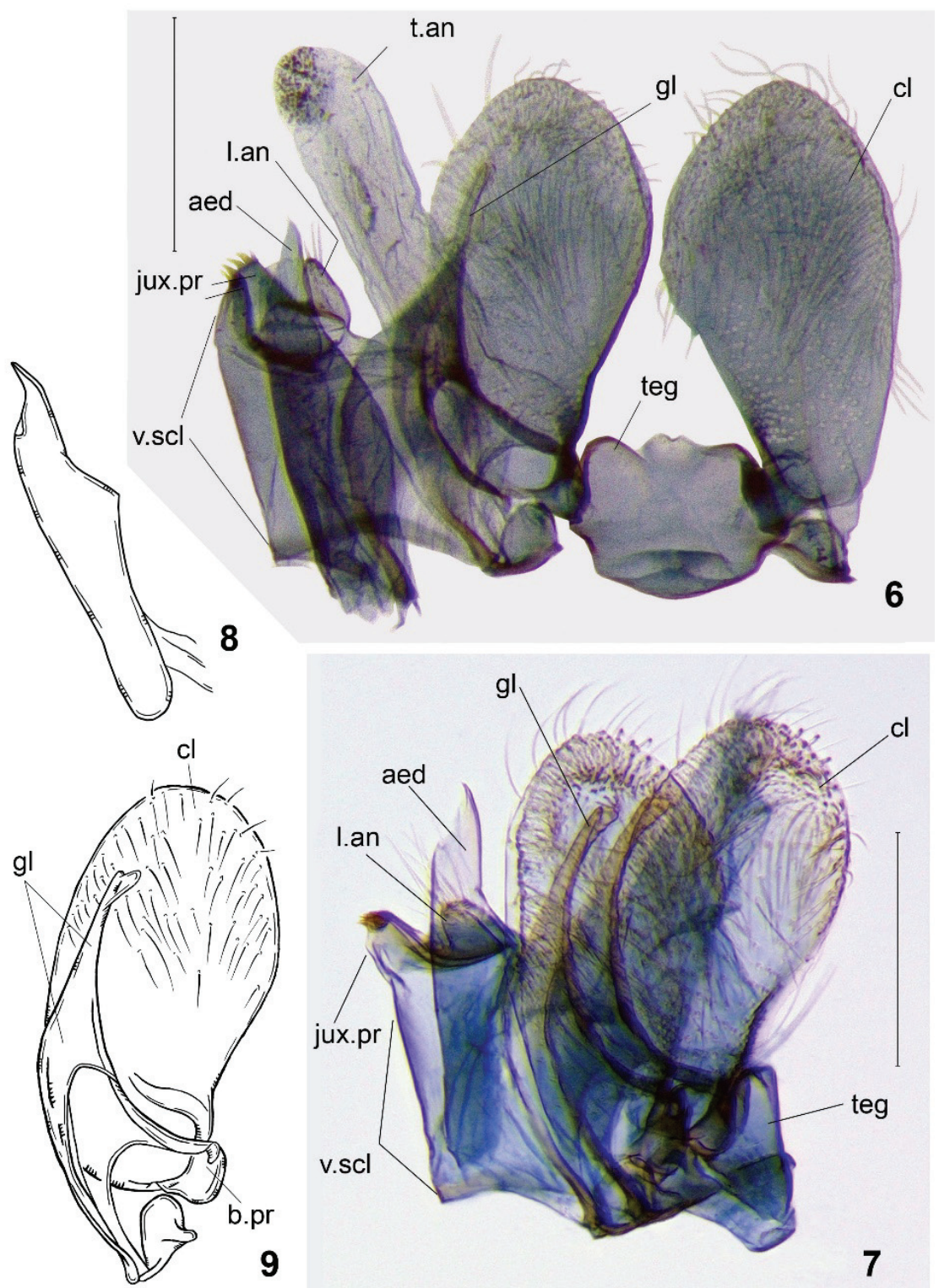

Figs 6-9. Neolitinia sulphurata sp. n., male genitalia. 6 - unrolled, holotype, 7 - lateral view, paratype, 8 - aedeagus, lateral view, 9 - cucullus with glandiductor, medial view. aed aedeagus, $b$. $p r$ - basal process of valva, $c l$ - cucullus, $g l$ - glandiductor; jux. $p r$ - process of juxta, l.an - lobe of anellus; t.an - tuba analis, teg - tegumen, v.scl - ventral sclerite. Scale bar $0.2 \mathrm{~mm}$. 
wing with two indistinct blackish spots along anal vein, distal part of wing with a greybordered black spot at middle and concolorous blackish-bordered or grey-bordered spot near tornus, apical part of wing with row of brown dots along costal and outer margins; fringe sandy along the apex and outer margin, and brownish or grey along dorsal margin (Figs 1,2). Hindwing and fringe grey or brownish. Forewing with $S c$ to costa at about $2 / 5$ of wing length; $R_{l}-R_{5}$ to costa, each separate at base; $M_{l}$ to dorsal margin below apex, separate at base; $M_{2}$ probably absent; $M_{3}$ separate; $C u A_{1}$ and $C u A_{2}$ separate basally, to dorsal margin; $1 A+2 A$ forked at base. Hindwing with $S c$ to costa beyond the middle; $R s$ to apex; $M_{l}$ to termen, $M_{2}$ probably absent, $M_{3}$ separate at base; $C u A_{1}$ and $C u A_{2}$ from $C u$ stem separately, $2 A$ short, to dorsal margin at $1 / 4$ of wing length (Fig. 3 ).
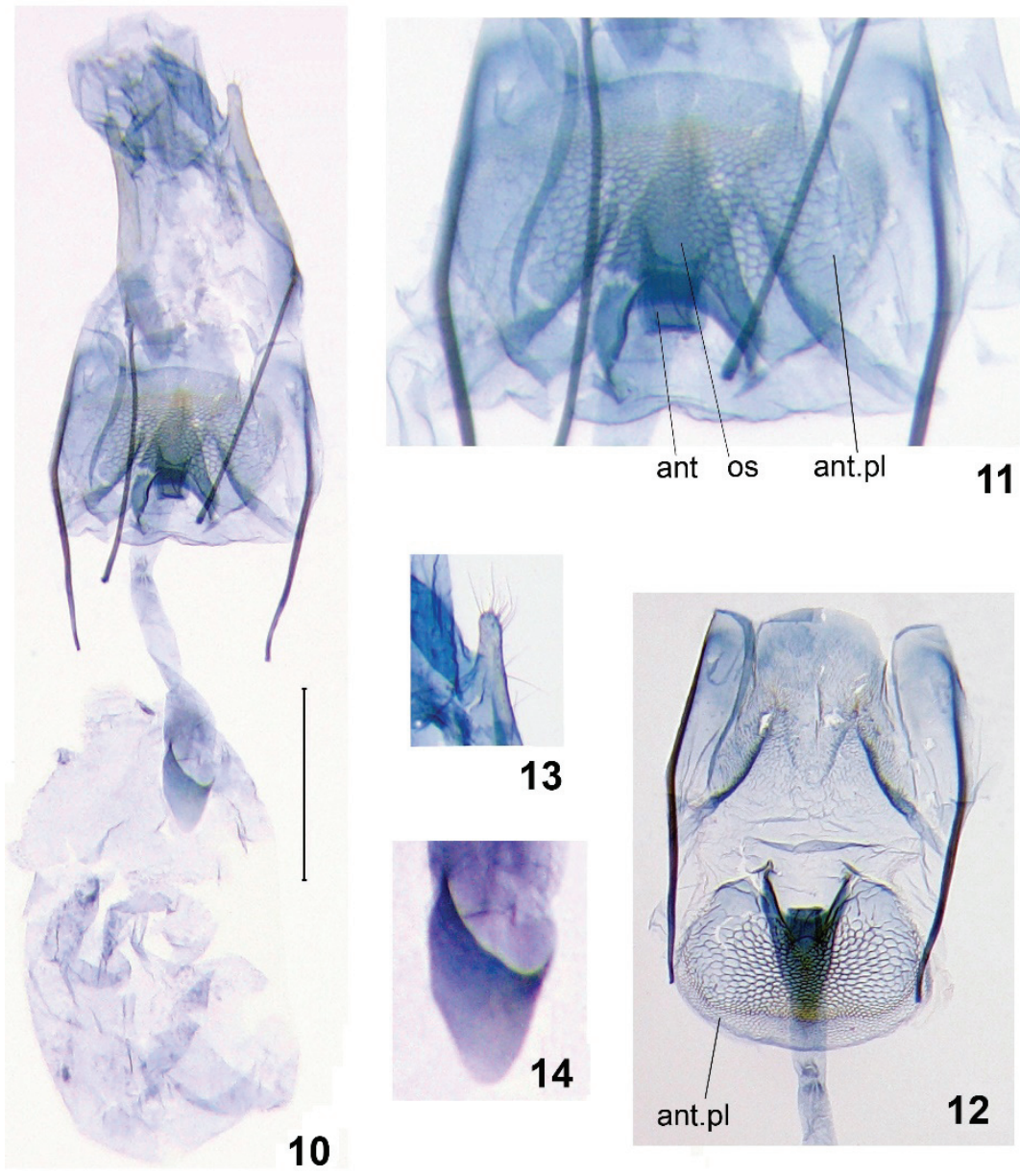

13
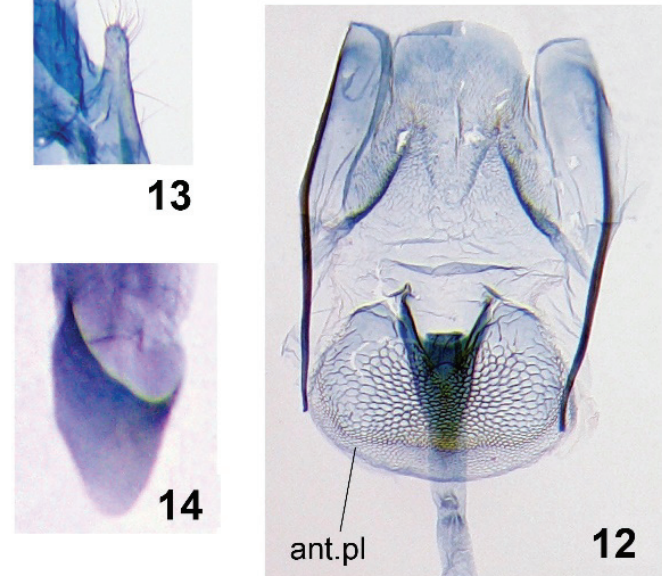

Figs 10-14. Neolitinia sulphurata sp. n., female genitalia. 10 - ventral view, paratype, scale bar $0.2 \mathrm{~mm} ; 11$ - antevaginal plate, ostium and antrum in a natural position; 12 antevaginal plate, turned down; 13 - papilla analis; 14 - signum; 11-14 - magnified. ant antrum, ant.pl - antevaginal plate, os - ostium. 
Forefemur and foretibia sandy with intensive brownish darkening, tarsomeres dark brown with white spot distally; midfemur grey, midtibia dark brown, with raised scales in proximal part and whitish collars at middle and in distal part; hindfemur grey with brown darkening on outer side, hindtibia sandy with brown darkening on outer side and brush of hair-like sandy scales on upper and lower margins in proximal part.

Second abdominal sternite with well-developed apodemes and sinuous venulae (Fig. 4). Invagination between the first and second abdominal tergites filled with a dense bundle of modified scales of unknown function (Fig. 5).

Male genitalia (Figs 6-9). Tegumen a small arched plate, emarginate posteriorly, anterior margin produced, triangular (Fig. 6). Cucullus with wide base, broadened beyond middle, its maximal width almost the same as half of length; glandiductor mediad cucullus, strongly inflated basally and narrowed towards apex, its base almost 9 times wider than distal part, its apex with rounded plate (Fig. 9). Vinculum, juxta and probably both sacculi fused into single ventral sclerite without distinct sutures, saccus absent. Distal part of ventral sclerite with a pair of processes, probably homologous to processes of juxta based on their position, bearing small strong thorns at apex and with a rounded notch between. Ventral sclerite with another pair of lobe-like setaceous processes laterally, according to their position homologous to processes of anellus. Aedeagus straight; apex truncate; inflated beyond middle, with ejaculatory ductus entering dorsally near base; fixed in sternal part of genitalia; enveloped latero-ventrally by both pairs of processes of ventral sclerite (Figs 7, 8).

Female genitalia (Figs 10-14). Ovipositor short, papillae anales sclerotized, with elongated digital apices (Fig. 13). Apophyses posteriores 2 times as long as free part of apophyses anteriores, the latter extending along lateral sides of 8th segment almost to its posterior margin. Sternal part of 8th segment separated by splits into medial with rounded posterior margin and lateral parts diverging anteriorly (Fig. 12). Ostium at level of anterior margin of 8th segment and at level of bottom of cut in honeycomb-patterned antevaginal plate covering ostium and antrum ventrally; antevaginal plate with triangular centered sclerite (Figs 11, 12). Antrum sclerotized and goblet-shaped; ductus bursae membranous, mainly tube-like, slightly widened towards the corpus bursae; corpus bursae oval, membranous; signum arched, triangular with rounded apex, located at opening of ductus bursae (Figs 10, 14).

DISTRIBUTION. East Malaysia (Sabah).

ETYMOLOGY. The species name is derived from the Latin "sulphuratus" meaning sulfuric (=sulphureous), because of the yellowish, sulfur-coloured forewing.

\section{DISCUSSION}

The presence of well-developed glandiductors; fusion of vinculum, juxta and both saculli into single ventral sclerite and a fixed aedeagus in the sternal part of the male genitalia are similarities shared with species in the tribe Litini (Gelechiidae), which includes more than 30 genera worldwide (Janse, 1958, 1960; Hodges, 1983; Huemer \& Karsholt, 1999; Ponomarenko, 2005; Lee \& Brown, 2008). According to phylogenetic analysis based on functional morphology of the male genitalia, the representatives of the tribe Litini are the most specialized in the clade Gelechiini + Gnorimoschemini + Litini (Ponomarenko, 2005). Genera of Litini are characterized by the male genitalia having significant morphological transformations accompanied by the disappearance of genital structures and muscles. Thus, the cucullus, being separated from the sacculus, completely lose connection with the valvar muscles (e.g., Exoteleia Wallengren, 1881; Carpatolechia Căpuşe, 1964), became weakly sclerotized structures, or disappear and functionally replaced by glandiductors (e.g., Stenolechia Meyrick, 1894; Schneidereria Weber, 1957; Teleiodes Sattler, 1960). The origin and probable function of the 
latter are described by the first author (Ponomarenko, 2005). Glandiductors are the sclerotized structures through which the membranous ductus of the glands of the genital segment pass. In fact, they are supporting structures for the glandular ductus and serve for delivery of the gland secretion, most likely into the genital tract of the female. Transformations of the ventral part of the genitalia in Litini are associated with the complete fusion of the sacculi, vinculum and juxta into a single, ventral sclerite accompanied by fixation of the aedeagus and partial disappearing of the valvar and phallic muscles (e.g., Recurvaria Haworth, 1828; Parastenolechia Kanazawa, 1985; Protoparachnonistis Omelko, 1986, etc.; and the genera listed above). Neolitinia gen. n. possesses the unique combination of characters listed above for several genera of Litini. Neolitinia gen. n., however, differs from the other members of the tribe by having large, broad, leaf-shaped cucullus and a small plate-like tegumen and the absence of an uncus and gnathos. Generally, the morphology of the male genitalia in the new genus corresponds to those in the genera of Litini. The resulting complex of characters in Neolitinia gen. n., both those shared with Litini and characters unique to the new genus, indicates it diverged very early from other genera of the tribe.

\section{ACKNOWLEDGMENTS}

We express our cordial appreciation to Dr. Mark A. Metz (USDA, Systematic Entomology Lab., Smithsonian Institution, National Museum of Natural History, Washington, U.S.A.) for correction of our manuscript according with English Grammar. Also, we grateful to Ph. D. K. A. Vinnikov (Laboratory of Ecology and Evolutionary Biology of the Aquatic Organisms, Far Eastern University, Vladivostok, Russia) for the opportunity to use equipment of Laboratory.

\section{REFERENCES}

Falkovitsh, M.I. \& Stekolnikov, A.A. 1978. Introduction. P. 5-27. In: Medvedev, G.S. (Ed.), Key to the insects of European part of Russia. Vol. 4. Lepidoptera. Part 1. Nauka, Leningrad. [In Russian]

Hodges, R.W. 1983. Gelechiidae. P. 19-25. In: Hodges, R.W., Dominick, R.B. et al. (Eds), Check List of the Lepidoptera of America North of Mexico. London.

Huemer, P. \& Karsholt, O. 1999. Gelechiidae I. In: Huemer, P., Karsholt, O. \& Lyneborg, L. (Eds), Microlepidoptera of Europe. Vol. 3. Apollo Books. Stenstrup. 356 pp.

ICZN (International Commission on Zoological Nomenclature). 1999. International Code of Zoological Nomenclature. Fourth edition. International Trust for Zoological Nomenclature, London, xxix $+306 \mathrm{pp}$.

Janse, A.J.T. 1958-1963. Moths of South Africa. Gelechiidae. VI. Pretoria. 284 pp., 138 pls.

Klots, A.B. 1970. Lepidoptera. P. 115-130. In: Tuxen, S.L. (Ed.) Taxonomist's glossary of genitalia in insects. Munksgaard, Copenhagen.

Lee, S \& Brown R.L. 2008. Revision of Holarctic Teleiodini (Lepidoptera: Gelechiidae). Zootaxa, 1818: 1-55.

Ponomarenko, M.G. 2005. Gelechiid moths (Lepidoptera, Gelechiidae) of the Palaearctica: functional morphology of the male genitalia, phylogeny and taxonomy. Meetings in memory of N.A. Cholodkovsky, St.-Petersburg, 58(1): 1-139. [In Russian]

Robinson, G.S. 1976. The preparation of slides of Lepidoptera genitalia with special reference to the Microlepidoptera. Entomologist's Gazette, 27: 127-132. 